\title{
Simav (Kütahya) Depremlerinin Jeotermal Sistemlerdeki Hidrojeokimyasal Değişimleri
}

\author{
Hydrochemical Changes in Geothermal Systems with Simav(Kütahya) Earthquakes
}

\author{
Özkan ATEŞ ${ }^{1}$, Salih Zeki TUTKUN ${ }^{2}$ \\ ${ }^{1}$ Çanakkale Onsekiz Mart Üniversitesi, Fen Bilimleri Enstitüsü, \\ Jeoloji Mühendisliği Anabilim Dal, 17100, Çanakkale \\ (e-posta: ozkan.ates@hotmail.com) \\ ${ }^{2}$ Çanakkale Onsekiz Mart Üniversitesi, Mühendislik Fakültesi, \\ Jeoloji Mühendisliği Bölümü, 17100, Çanakkale
}

\section{ÖZ}

Kütahya ve Simav Fayları arasında kalan bölgede birçok jeotermal alan - Eynal, Çitgöl ve Naşa (Simav), Ilıcasu-Abide (Gediz), Muratdağı, Yoncalı, Emet, Yeniceköy, Dereli, Göbel, Ilıca (Harlek), Sefaköy ve Hamamköy(Hisarcık), Şaphane- bulunmaktadır. Türkiye Diri Fay Haritalarında da aktiffay olarak gösterilen Simav Fayı'nın hemen kuzeyinde kalan çalışma alanı, Simav (Kütahya) civarında yer almaktadır. Bölge aletsel dönemdeki depremler açısından oldukça aktif bir bölge olduğu gibi jeotermal sistemler bakımından da oldukça zengin bir bölgedir. Bu jeotermal alanların çoğu da aktif fay zonları üzerinde yer almaktadır. Bu bölgenin büyük bölümü, geçmişte olduğu gibi günümüzde de deprem riski altında bulunmaktadır. Aletsel dönemde, Mayıs 2010-Mayıs 2013 tarihleri arasında bu bölge ve yakın civarında $M=3.0$ ten büyük yaklaşı 735 adet deprem olmuştur. Ayrıca, Gediz'de 1970 yılında 1 adet M=6.0 dan büyük ve Simav'da 2009, 2011 ve 2012 yıllarında da büyüklüğü 5.0 ve 5.0 ten büyük depremler meydana gelmiştir. Kütahya ili Simav ilçesinde bulunan Eynal, Çitgöl ve Naşa jeotermal alanlarındaki sıcak su kaynaklarından 2010 ile 2013 yılları arasında yaklaşık üç yıl süren bir izleme çalışması yapılmıştır. Çalışma alanındaki jeotermal kaynaklar ile aktif fayların ilişkisi, jeotermal suların hidrojeokimyasal özellikleri ile bölgedeki yoğun deprem aktivitesi ile ilişkilendirilmeye çalışılmıştır. İzleme döneminde meydana gelen özellikle $\mathrm{M}=5.0$ ve daha büyük depremlerle birlikte jeotermal kaynakların fiziko-kimyasal özelliklerinde sıcaklık artışı, $\mathrm{Cl}^{-}$iyonu değerinde artış ve $\mathrm{SO}_{4}^{-2}$ iyonu değerinde azalış gibi değişimler elde edilmiştir.

Anahtar Kelimeler: Aktif Fay, Deprem, Jeotermal Enerji, Kütahya, Simav 


\section{ABSTRACT}

Many geothermal fields in Kütahya including Eynal, Çitgöl ve Naşa (Simav), Ilıcasu-Abide (Gediz), Muratdağı, Yoncall, Emet, Yeniceköy, Dereli, Göbel, Ilıca (Harlek), Sefaköy ve Hamamköy (Hisarcık) and Şaphane are located between Kütahya and Simav active faults in Western Turkey. Studied area in Simav (Kütahya) is situated in the north of Simav Fault and indicated as an active fault zone in the active fault maps of Turkey. This area is fairly active region in terms of earthquakes occurred in the instrumental period and has many geothermal systems. Most of these geothermal fields are located on active fault zones. Approximately 735 earthquakes (M>3.0) occurred between May 2010 to May 2013, including 1 earthquake with the magnitude of greater than 6.0 at Gediz in 1970 and 4 earthquakes with the magnitude of greater than 5.0 at Simav in 2009, 2011 and 2012. Data from a monitoring study during three years (20102013) from thermal springs in Eynal, Çitgöl ve Naşa geothermal fields which located at Simav (Kütahya) were used in this study. This study tried to find out relationship between geothermal springs and active faults, and relationship between hydrochemical features of geothermal waters and high seismic activity. The results of this study indicated that some physic-chemical parameters of geothermal waters change especially increasing temperature, increasing $\mathrm{Cl}^{-}$ion value and decreasing $\mathrm{SO}_{4}^{-2}$ ion value with earthquakes with has 5.0 and greater magnitude value.

Key Words: Active Fault, Earthquake, Geothermal Energy, Kütahya, Simav

\section{GİRIŞ}

Yeraltısuyu bileşimlerindeki fiziksel ve kimyasal değişimlerin deprem öncesinde oluşan ilk sarsıntılarla başladı̆̆ı ve enerji boşalımı ile maksimum değerine ulaştığı, sonra zamanla normale döndükleri bilinmektedir (Şimşek ve Y1ldırım, 2000). Deprem öncesi, depremle birlikte ve deprem sonrası yeni kaynak oluşumları veya mevcut kaynakların kaybolması da olağandır. Sıcak ve mineralli su kaynaklarındaki değişimlerin bir depremin önceden belirlenebilmesi amaciyla sağlıklı olarak kullanılabilmesi için, bu kaynak bölgelerinin ayrıntılı jeolojik özelliklerinin bilinmesi gereklidir. 17 Ağustos 1999 İzmit ve 12 Kasım 1999 Düzce depremlerinde de bazı jeotermal kaynak ve kuyu sularında fiziksel ve kimyasal değişimler izlenmiştir (Şimşek ve Yıldırım, 2000). Bu çalışmada, Kütahya ili Simav ilçesi güneyi boyunca uzanan Simav Fayı üzerinde yer alan üç farklı jeotermal alanda bulunan sıcak su sondaj kuyuları belirlenmiştir. Bu kuyuların başında yerinde ölçümler ( $\mathrm{pH}$, iletkenlik-EC ve sicaklık- $\mathrm{T}^{0}$ ) ve alınan sicak su örneklerinden hidrojeokimyasal analizler $\left(\mathrm{Ca}^{+2}, \mathrm{Mg}^{+2}, \mathrm{Na}^{+}\right.$, $\mathrm{K}^{+}, \mathrm{SO}_{4}=\mathrm{Cl}^{-}$ve $\mathrm{HCO}_{3}^{-}$) yapilarak termal suların hidrojeokimyasal özellikleri ortaya çıkarılmıştır. Örnekleme ve yerinde ölçümler düzenli olarak belirli peryotlarda gerçekleştirilmiştir. $\mathrm{Bu}$ çalışmada, bir depremin önceden tahmin edilmesine de katkı sağlamak amacıyla, sismik açıdan da oldukça aktif olan Simav civarında yer alan sıcak su kaynaklarının hidrojeokimyasal özellikleri ve bölgenin aktif tektonik yapısı ile olan ilişkisinin ortaya çıkarılması amaçlanmıştır.

\section{MATERYAL VE YÖNTEM}

Bu çalışmada Kütahya ili, Simav ilçesi kuzeyinde yer alan jeotermal alanlarda aktif fay hatları ile ilişkili sıcak su kaynakları belirlenmiştir. Bununla beraber, jeotermal alanların ve yakın civarının jeoloji ve aktif fay haritaları revize edilmiştir. Ayrıca arazide belirlenen üç adet jeotermal 
alandaki sıcak su kaynak ve sondajlarında 3 y1l içerisinde 10 örnekleme döneminde yerinde ölçüm ve su örneklemesi gerçekleştirilmiştir. Kuyuların başında $\mathrm{pH}$, iletkenlik (EC) ve sıcaklık $\left(\mathrm{T} \mathrm{C}^{0}\right.$ ) ölçümleri yapılmıştır. Sıcak suların $\mathrm{HCO}_{3}^{-}$ analizleri laboratuvarda titrasyon yöntemi ile yapılmıştır. Alınan sıcak su örneklerinin kimyasal analizlerinden major anyon, katyon analizleri ise Çanakkale Onsekiz Mart Üniversitesi, Bilim ve Teknoloji Uygulama ve Araştırma Merkezi Laboratuvarlarında ICP-OES $\left(\mathrm{Ca}^{+2}, \mathrm{Mg}^{+2}, \mathrm{Na}^{+}, \mathrm{K}^{+}\right)$ ve iyon kromotografisi $\left(\mathrm{SO}_{4}{ }^{=}\right.$ve $\left.\mathrm{Cl}^{-}\right)$cihazlarında yapılmıştır.

\section{ÇALIŞMA SAHASININ JEOLOJISİ, AKTİF TEKTONİĞİ ve DEPREMSELLİĞİ}

Çalışma alanı Orta-Batı Anadolu'da Kütahya ili, Simav ilçesi ve yakın çevresi ile sınırlanan bir alandır (Şekil 1).

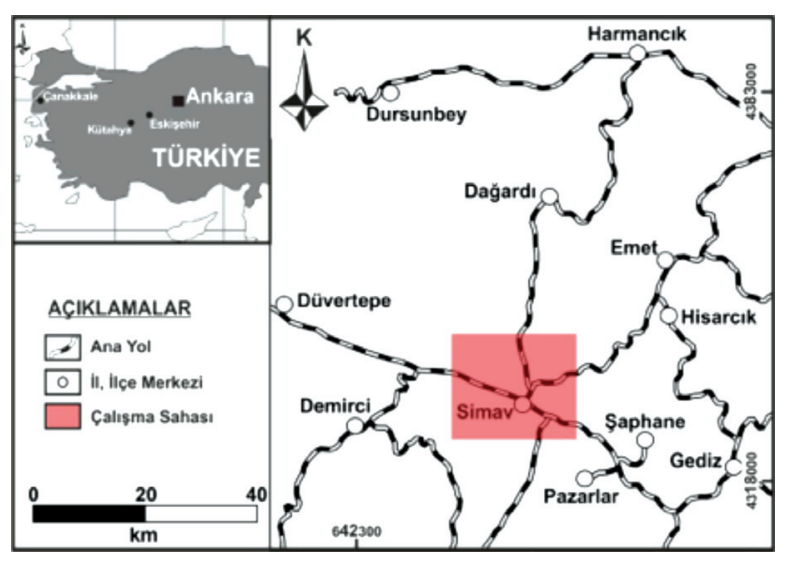

Şekil 1. Çalışma alanın yer bulduru haritası

Figure 1. Location map of study area
Çalışma alanı ve yakın civarı jeolojik olarak Menderes Masifi'nin en kuzey ucunu temsil eder. Bu kesim günümüzde Simav Fayı ile sınırlıdır. Masifin kuzeyindeki alanlarda, OligoMiyosen yaşlı plütonik kayaçlar yer almaktadır. $\mathrm{Bu}$ birimleri üzerleyen Miyosen yaşlı volkanik, kırıntılı ve karbonatlı kayaçlar geniş yayılımlar sunarken, Pliyo-Kuvaterner yaşlı karasal kırıntılı ve karbonatlarla örtülmekte ve çok genç volkanik kayaçlar tarafindan da kesilmektedir (Konak, 2002).

Çalışma alanının temelinde; gnays, migmatit ve şist türü metamorfik kayaçlardan oluşan Paleozoyik yaşlı Menderes metamorfitleri vardır (Akdeniz ve Konak, 1979). Bu metamorfik kayaçları keser durumda granodiyoritmonzogranitten oluşan Paleosen-Eosen yaşlı Simav granitoidleri yer alır (Akdeniz ve Konak, 1979; Yücel ve diğ., 1983). Bu kayaçların üzerinde uyumsuz olarak Orta-Üst Miyosen yaşlı konglomera, kumtaşı, marn, kiltaşı, killi kireçtaşı ve tüf gibi sedimanter ve volkanik kayaçlardan oluşan bir istif yer alır (Gün ve diğ., 1979; Akdeniz ve Konak, 1979). Pliyo-Kuvaterner yaşlı Naşa bazaltı ise bölgedeki en genç volkanik etkinliktir (Ercan ve diğ., 1982; Yücel ve diğ., 1983). Tüm bu kaya birimlerini de Kuvaterner yaşlı alüvyon uyumsuz olarak örter (Şekil 2). 


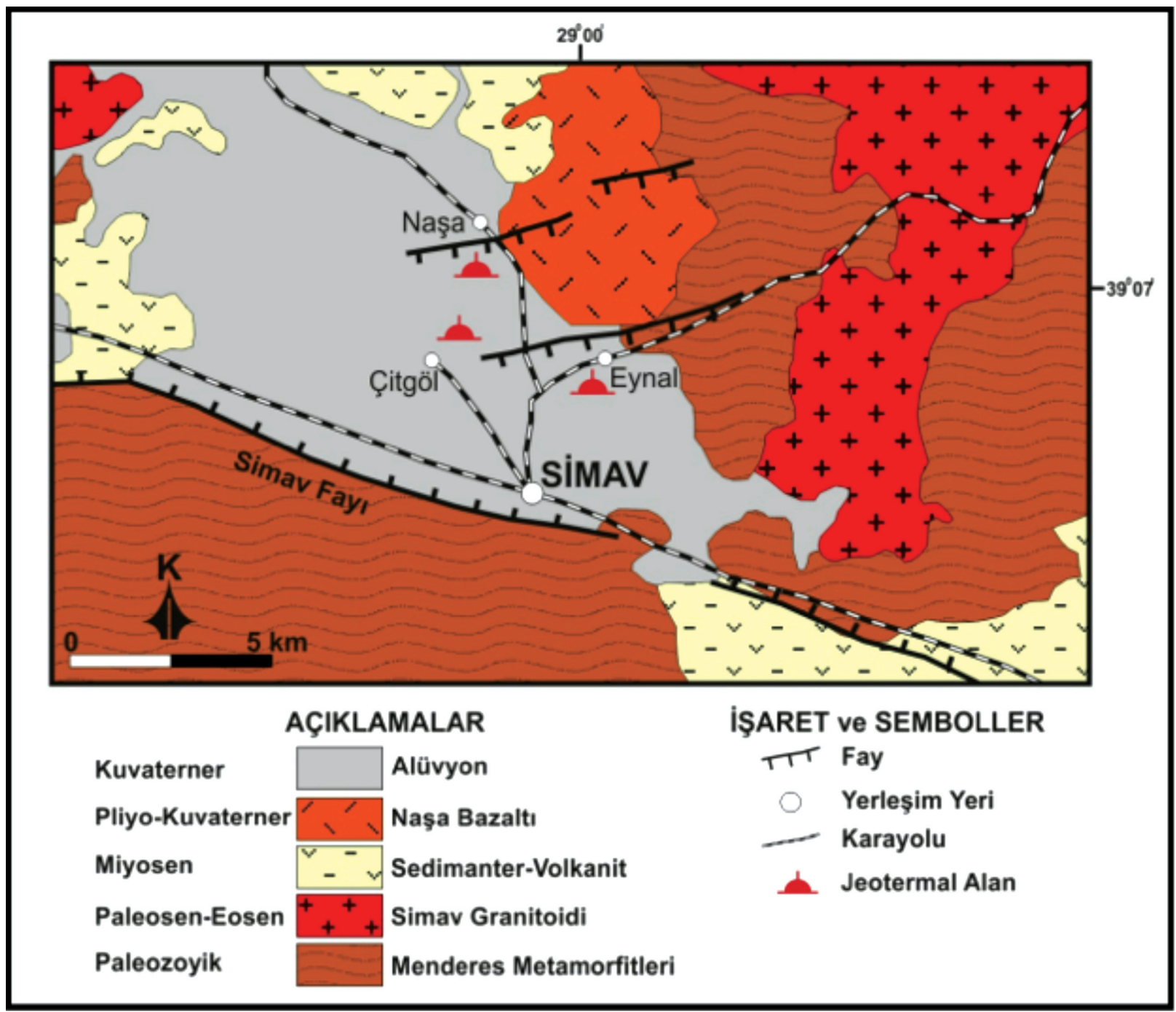

Şekil 2. Çalışma alanı ve yakın civarının jeoloji haritası (Konak, 2002'den değiştirilerek) Figure 2. Geological map of study area and surroundings (modified from Konak, 2002)

Çalışma alanda gözlenen fayların çoğunluğu eğim atımlı normal fay karakterindedir. $\mathrm{Bu}$ fayların genel doğrultuları KB-GD, BKB-DGD ve D-B dır (Yücel ve diğ., 1983). Bu faylardan en önemlisi ve aktif olanı çalışma sahası güneyi boyunca uzanan, BKB-DGD doğrultulu, kuzeye eğimli Simav Fayı'dır (Şekil 3). Simav Fayı, Simav grabenini güneyden sınırlayan yaklaşık 60 km uzunluğunda bir faydır. Fayın başlangıçta sağ yanal doğrultu atımlı bir fay olarak çalıştığı bilinse de özellikle Kuvaterner'de, Batı Anadolu'da etkin olan genel KKD-GGB doğrultulu genişleme tektoniği içerisinde bir rejim değişikliğine maruz kalmıştır ve günümüzde normal bir fay olarak çalışmaktadır (Özden ve diğ., 2012). 


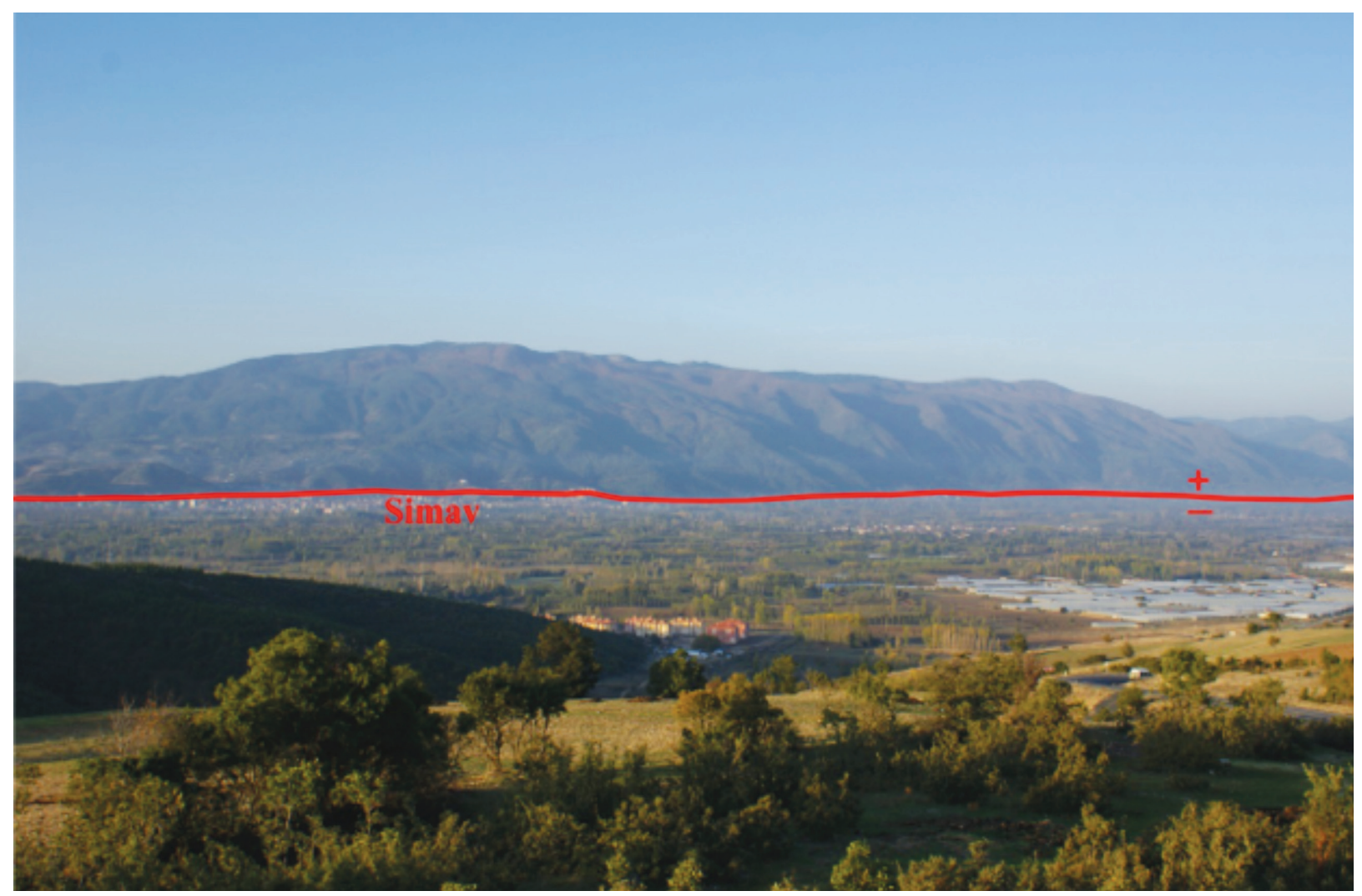

Şekil 3. Simav fayı (bakış yönü kuzeyden güneye)

Figure 3. Simav fault (view from north to south)

Çalışma alanı ve yakın çevresinde depremsellik açısından oldukça yoğun bir aktivite söz konusudur. Bölgede aletsel dönemde meydana gelmiş en büyük deprem 28 Mart 1970 y1lında meydana gelmiş $\mathrm{M}=7.2$ büyüklüğündeki Gediz depremidir. Bu çalışmanın başladığı tarih olan Mayıs 2010'dan Mayıs 2013 tarihine kadar M $\geq 3$ büyüklügünde yaklaşık 735 adet deprem meydana gelmiştir (Şekil 4). Bu depremlerin en büyüğü ve hasar yap1cı olan deprem 19 Mayıs 2011 tarihinde saat 20:15 te meydana gelen Simav merkezli $\mathrm{M=5.9}$ büyüklüğündeki depremdir (Şekil 5). Ayrıca 27 Haziran 2011 tarihinde M=5.0 büyüklüğünde ve 3 Mayıs 2012 tarihinde $M=5.4$ büyüklüğünde iki adet orta büyüklükte deprem meydana gelmiştir (Çizelge 1).

Çizelge 1. Çalışma alanı ve yakın çevresinde meydana gelen $M \geq 5,0$ depremler (Mayıs 2010-Nisan 2013) (www.deprem.gov.tr)

Table 1. M $\quad$ $\geq 5.0$ earthquakes occured in study area and surroundings (May 2010-April 2013) (www.deprem.gov.tr)

\begin{tabular}{cccccccc}
\hline Say1 & Tarih (UTC) & Saat & Enlem & Boylam & Yer & M & Derinlik $(\mathrm{km})$ \\
\hline 1 & 03.05 .2012 & $15: 20$ & 39.1245 & 29.110 & KÜTAHYA - SİMAV & 5.4 & 10.59 \\
2 & 27.06 .2011 & $21: 13$ & 39.1108 & 29.026 & KÜTAHYA - SİMAV & 5.0 & 18.27 \\
3 & 19.05 .2011 & $20: 15$ & 39.1328 & 29.082 & KÜTAHYA - SIMAV & 5.9 & 24.46 \\
\hline
\end{tabular}




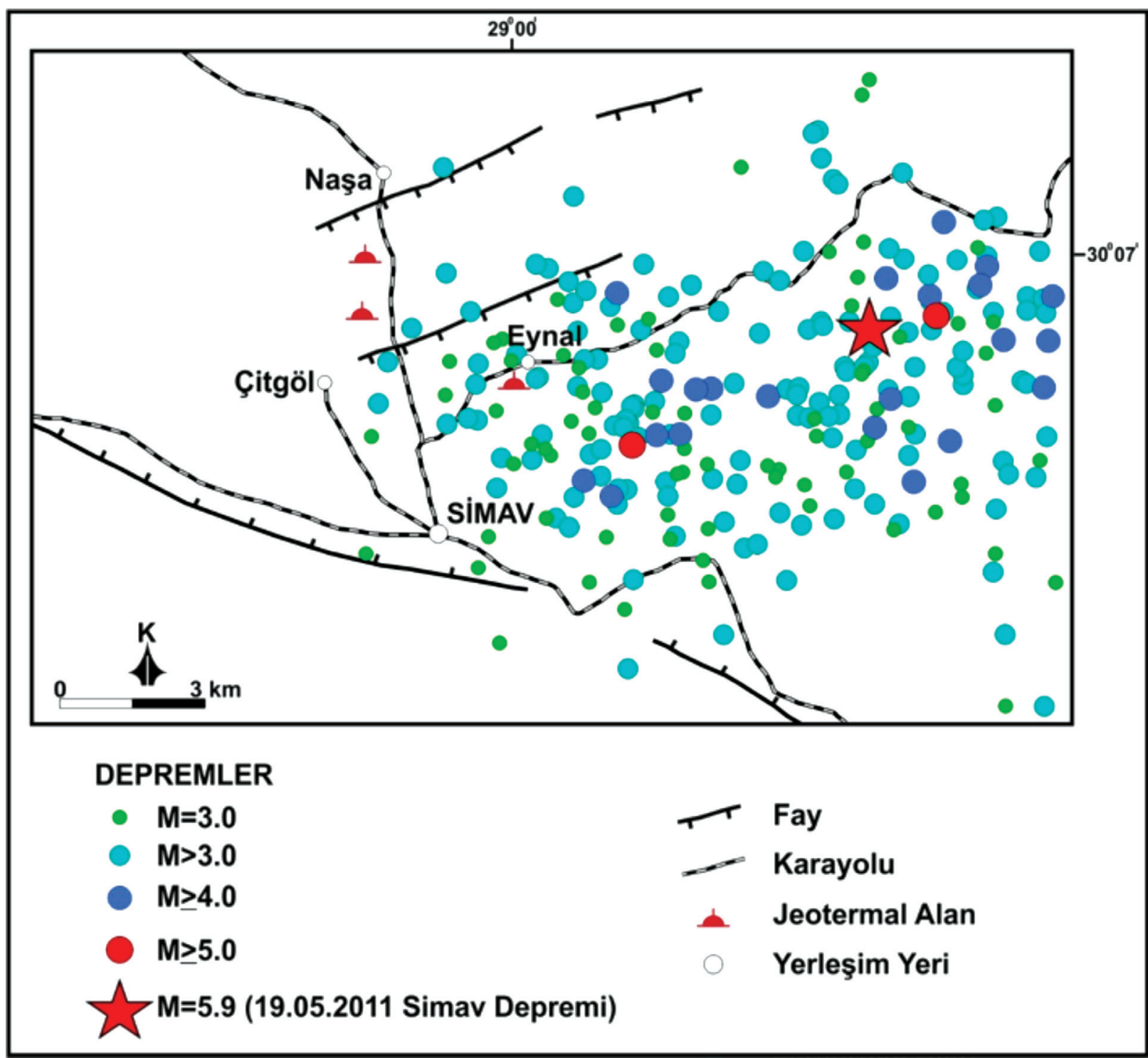

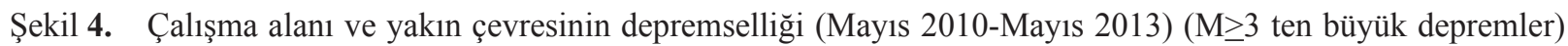
(www.deprem.gov.tr)

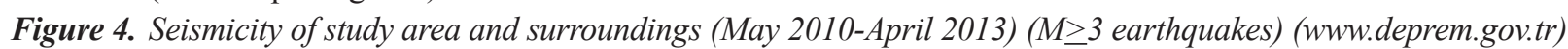




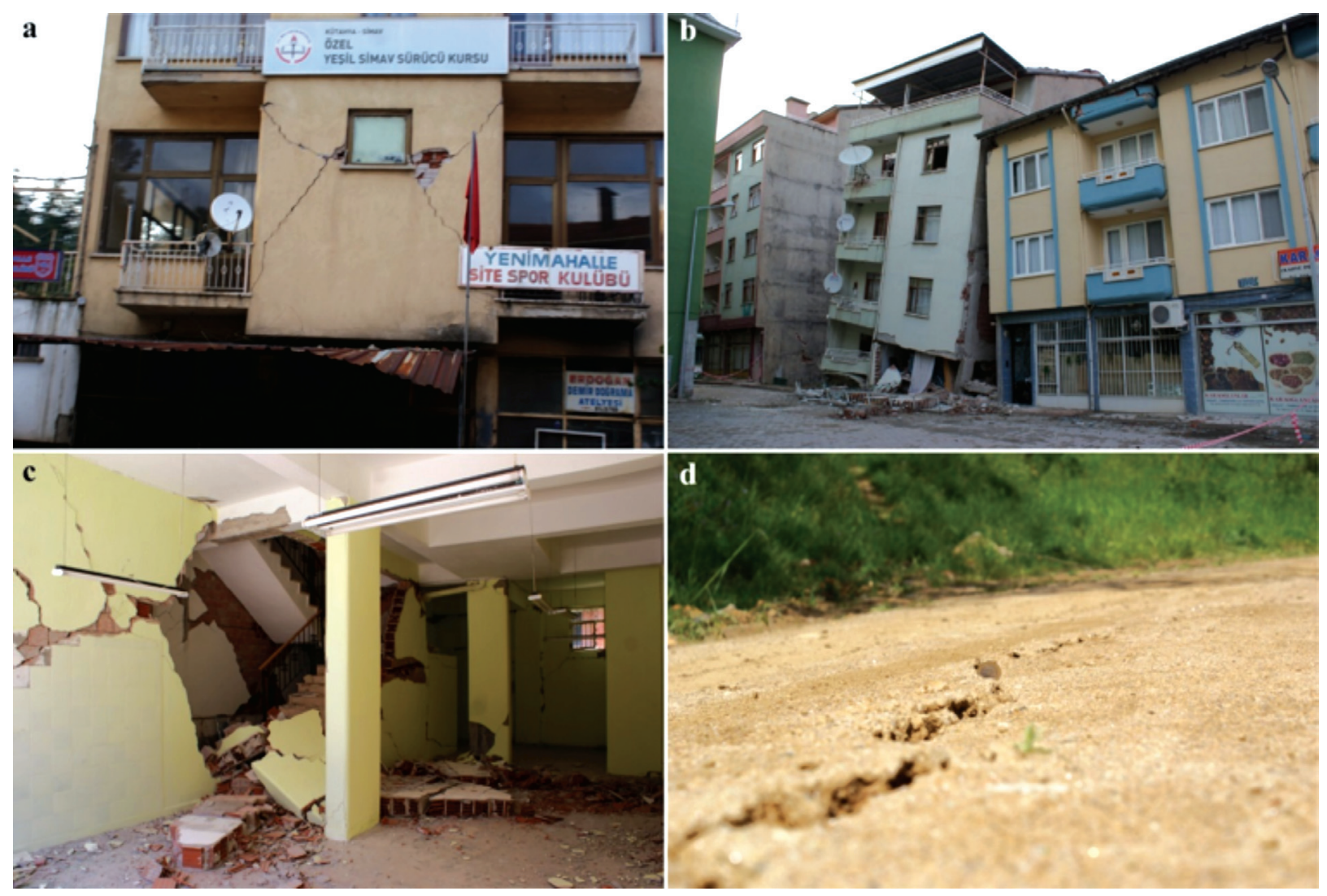

Şekil 5. Simav depremi sonrası meydana gelen yapısal hasarlar (a, b, c) ve yüzey çatlakları (d)

Figure 5. Sructural damages after Simav earthquake $(a, b, c)$ and surface rupture (d)

ÇALIŞMA ALANINDAKİ JEOTERMAL ALANLARIN HIDROJEOKIMYASAL ÖZELLIKLERİ

Bu çalışmada Mayıs 2010-Mayıs 2013 tarihleri arasında Simav ilçesindeki Eynal, Çitgöl ve Naşa jeotermal alanlarında belirlenen sıcak su sondaj kuyularından periyodik olarak yerinde ölçüm ve su örnekleme çalışmaları yapılmıştır (Çizelge 2). Tüm jeotermal alanlarda doğal sıcak su çıkış kaynağı bulunmadığından en yüksek yüzey çıkış sıcaklığına sahip sondaj kuyuları örnekleme yeri olarak belirlenmiştir. Bu çalışmalar 3 y1l içerisinde 10 örnekleme döneminde, 28 Mayıs 2010, 13 Mayıs 2011, 21 Mayıs 2011, 14 Temmuz 2011, 26 Kasim 2011, 23 Nisan 2012, 25 Temmuz 2012, 25 Ağustos 2012, 03 Kasım 2012 ve 30 Mart 2013 tarihlerinde yapılmıştır. Alınan su örneklerinden laboratuvarda yapilan analizler sonucu sadece majör anyon ve katyon analiz değerleri belirlenerek hidrojeokimyasal değerlendirmeler için sayısal diyagramlara aktarılmıştır. 
Çizelge 2. Çalışma alanında incelenen jeotermal alanlara ait lokasyon bilgileri

Table 2. Location of geothermal areas in study area

\begin{tabular}{cccccc}
\hline Lokasyon & \multirow{2}{*}{ İçe } & Şehir & $\begin{array}{c}\text { Boylam } \\
(\mathrm{E})\end{array}$ & $\begin{array}{c}\text { Enlem } \\
(\mathrm{N})\end{array}$ & $\begin{array}{c}\text { Kot } \\
(\mathrm{m})\end{array}$ \\
\hline Çitgöl & Simav & Kütahya & 35 S 0669955 & 4333650 & 797 \\
Naşa & Simav & Kütahya & 35 S 0669446 & 4334708 & 793 \\
Eynal & Simav & Kütahya & 35 S 0672468 & 4332920 & 829 \\
\hline
\end{tabular}

\section{Eynal Jeotermal Alanı}

Eynal jeotermal alanı, Simav (Kütahya) ilçe merkezinin yaklaşı $4 \mathrm{~km}$ kuzeyinde yer almaktadır. Eynal jeotermal alanında MTA nın 2004 yılında açmış olduğu yaklaşık 208 m derinliğindeki E-9 sondaj kuyusunda yerinde ölçüm ve su örneklemesi yapılmıştır (Şekil 6). Bu sondaj kuyusundan 3 yıl içerisinde 10 örnekleme döneminde yerinde ölçüm ve su örnekleme çalışması yapılarak termal suyun fiziksel ve kimyasal özellikleri belirlenmiştir (Çizelge 3).

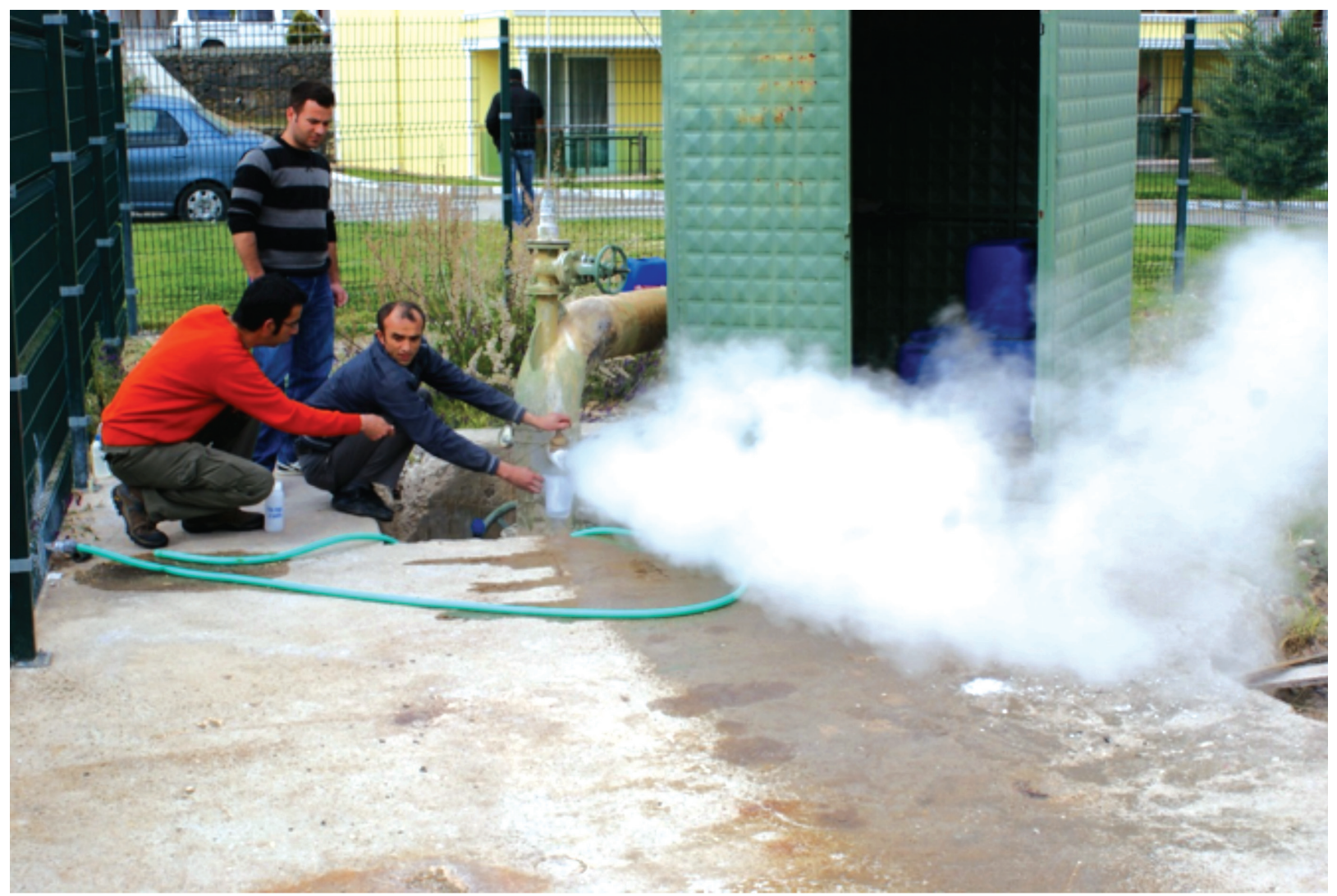

Şekil 6. Eynal Jeotermal Alanı (E-9 Kuyusu)

Figure 6. Eynal Geothermal Field (E-9 Drilling) 
Çizelge 3. Eynal Jeotermal Alanındaki sıcak suyun majör iyon derişimleri

Table 3. Major ion concentration of thermal water in Eynal Geothermal Field

\begin{tabular}{|c|c|c|c|c|c|c|c|c|c|c|}
\hline Tarih & $\begin{array}{c}\mathrm{T} \\
\left({ }^{0} \mathrm{C}\right)\end{array}$ & pH & $\begin{array}{l}\text { EC } \\
(\mu \mathrm{S} / \\
\mathrm{cm})\end{array}$ & $\begin{array}{c}\mathrm{Na}^{+} \\
(\mathrm{mg} / \mathrm{l})\end{array}$ & $\begin{array}{c}\mathrm{K}^{+} \\
(\mathrm{mg} / \mathrm{l})\end{array}$ & $\begin{array}{c}\mathrm{Ca}^{+2} \\
(\mathrm{mg} / \mathrm{l})\end{array}$ & $\begin{array}{l}\mathrm{Mg}^{+2} \\
(\mathrm{mg} / \mathrm{l})\end{array}$ & $\begin{array}{c}\mathrm{Cl}^{-} \\
(\mathrm{mg} / \mathrm{l})\end{array}$ & $\begin{array}{l}\mathrm{SO}_{4}^{-2} \\
(\mathrm{mg} / \mathrm{l})\end{array}$ & $\begin{array}{l}\mathrm{HCO}_{3}^{-} \\
(\mathrm{mg} / \mathrm{l})\end{array}$ \\
\hline 28.05 .2010 & 86,40 & 8,25 & 2230 & 161,52 & 38,33 & 8,62 & 0,47 & 68,10 & 421,60 & 141,00 \\
\hline 13.05 .2011 & 82,10 & 8,83 & 2080 & 356,18 & 48,98 & 6,38 & 0,37 & 256,70 & 155,90 & 350,14 \\
\hline 21.05 .2011 & 83,50 & 8,47 & 2140 & 370,32 & 51,68 & 11,04 & 0,62 & 288,60 & 163,11 & 395,28 \\
\hline 14.07 .2011 & 90,40 & 8,11 & 2160 & 434,95 & 66,15 & 8,78 & 0,74 & 296,60 & 177,98 & 418,77 \\
\hline 26.11.2011 & 87,00 & 8,63 & 2181 & 229,89 & 77,69 & 12,79 & 0,45 & 88,51 & 525,70 & 321,47 \\
\hline 23.04 .2012 & 92,00 & 8,70 & 2176 & 253,32 & 65,66 & 10,72 & 0,26 & 81,22 & 485,88 & 348,01 \\
\hline 25.07 .2012 & 83,00 & 8,59 & 2532 & 242,87 & 76,94 & 10,99 & 0,64 & 84,73 & 507,85 & 466,35 \\
\hline 25.08 .2012 & 80,80 & 8,65 & 2478 & 222,23 & 94,35 & 16,10 & 0,61 & 91,10 & 513,40 & 421,23 \\
\hline 03.11 .2012 & 79,00 & 8,36 & 2492 & 218,01 & 64,37 & 10,06 & 0,53 & 82,17 & 496,71 & 371,19 \\
\hline 30.03 .2013 & 87,4 & 8,57 & 2126 & 228,70 & 142,25 & 9,75 & 0,61 & 86,84 & 548,57 & 401,45 \\
\hline
\end{tabular}

Major anyon/kayton analiz sonuçları, su tipini belirlemek üzere Piper ve Schoeller hidrojeokimsayal değerlendirme amaçlı sayısal diyagramlarına aktarılmıştır. Alandaki termal su tipleri incelendiğinde, Eynal jeotermal alanındaki E-9 kuyusundaki su tipi $\mathrm{Na}^{+}-\mathrm{SO}_{4}^{-2}-\mathrm{HCO}_{3}^{-}$tipi olarak belirlenmiştir (Şekil 7).
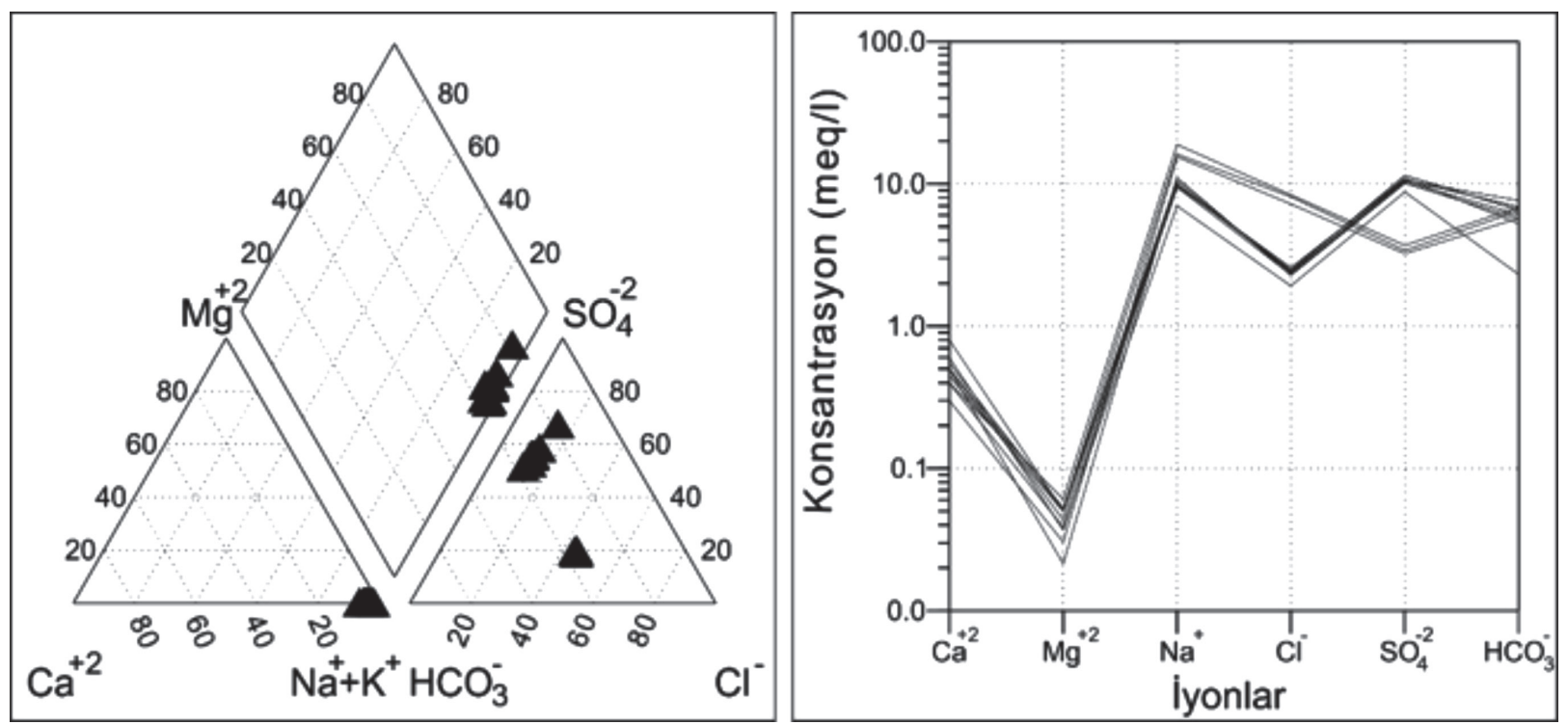

Şekil 7. Eynal kaynağından alınan verilere göre hazırlanmış Piper ve Schoeller diyagramları

Figure 7. Piper and Schoeller diagrams of Eynal thermal water 


\section{Naşa Jeotermal Alanı}

Naşa jeotermal alanı, Simav (Kütahya) ilçe merkezinin yaklaşık $6 \mathrm{~km}$ kuzeybatısında yer almaktadır. Naşa jeotermal alanında MTA nın 1986 yılında açmış olduğu yaklaşık $200 \mathrm{~m}$ derimliğindeki N-1 nolu sondaj kuyusundan yerinde ölçüm ve su örneklemesi yapılmıştır (Şekil 8). Bu sondaj kuyusundan 10 örnekleme döneminde yerinde ölçüm ve su örnekleme çalışması yapılarak termal suyun fiziksel ve kimyasal özellikleri belirlenmiştir (Çizelge 4).

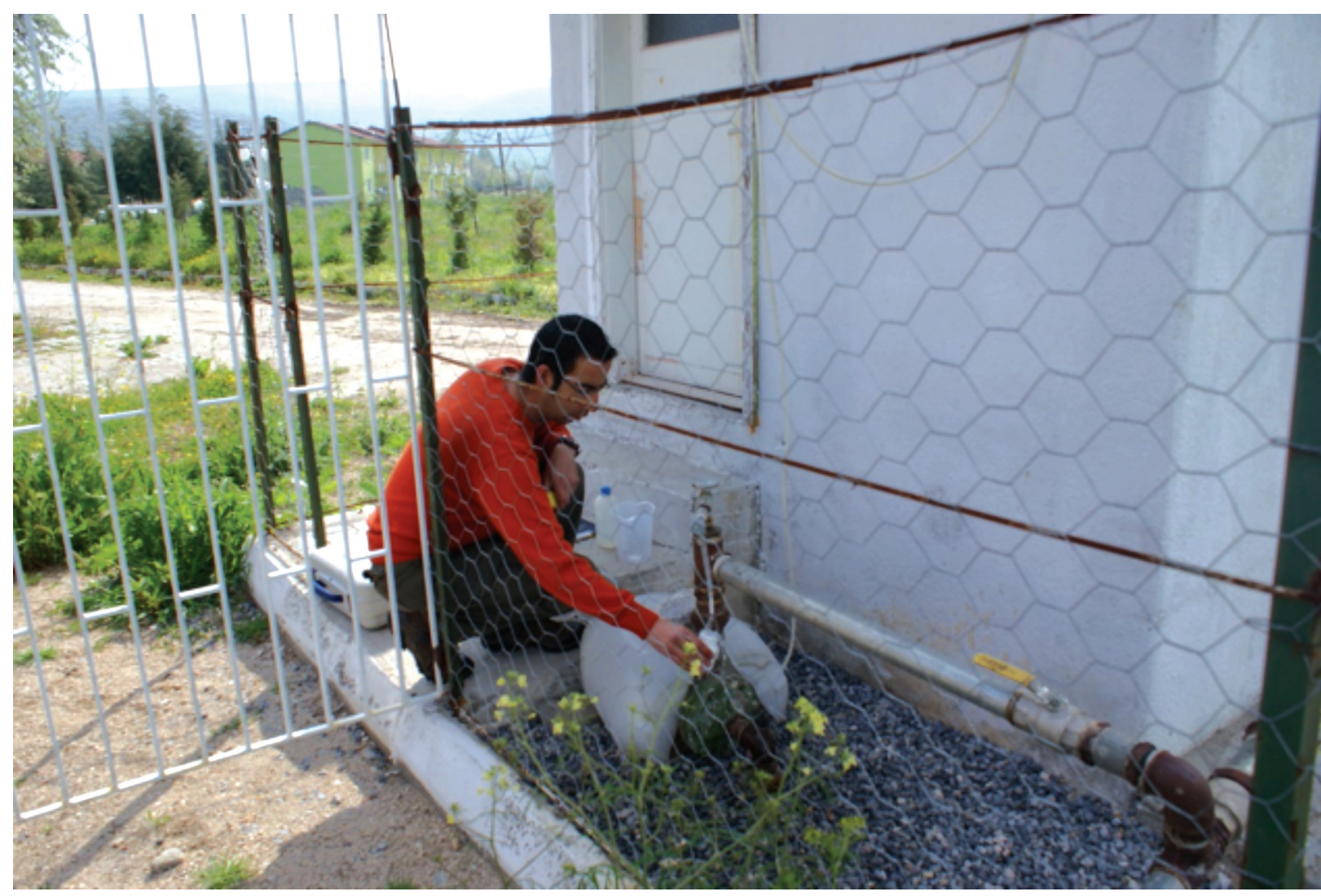

Şekil 8. Naşa Jeotermal Alanı (N-1 Kuyusu)

Figure 8. Naşa Geothermal Field (N-1 Drilling) 
Çizelge 4. Naşa Jeotermal Alanındaki sıcak suların majör iyon derişimleri

Table 4. Major ion concentration of thermal water in Naşa Geothermal Field

\begin{tabular}{ccccccccccc}
\hline Tarih & $\mathbf{T}$ & $\mathbf{p H}$ & $\begin{array}{c}\mathbf{E C} \\
(\boldsymbol{\mu} \mathbf{S} /\end{array}$ & $\begin{array}{c}\mathbf{N a}^{+} \\
\mathbf{( m g} / \mathbf{l})\end{array}$ & $\begin{array}{c}\mathbf{K}^{+} \\
(\mathbf{m g} / \mathbf{l})\end{array}$ & $\begin{array}{c}\mathbf{C a}^{+2} \\
(\mathbf{m g} / \mathbf{l})\end{array}$ & $\begin{array}{c}\mathbf{M g}^{+2} \\
(\mathbf{m g} / \mathbf{l})\end{array}$ & $\begin{array}{c}\mathbf{C l}^{-} \\
(\mathbf{m g} / \mathbf{l})\end{array}$ & $\begin{array}{c}\mathbf{S O}_{4}^{-2} \\
(\mathbf{m g} / \mathbf{l})\end{array}$ & $\begin{array}{c}\mathbf{H C O}_{3}^{-} \\
(\mathbf{m g} / \mathbf{l})\end{array}$ \\
\hline 28.05 .2010 & 52,00 & 7,22 & 1553 & 288,56 & 19,60 & 32,29 & 9,25 & 44,50 & 293,15 & 488,00 \\
13.05 .2011 & 62,20 & 7,54 & 1546 & 207,79 & 28,80 & 61,88 & 9,81 & 198,10 & 123,48 & 335,50 \\
21.05 .2011 & 62,20 & 7,44 & 1573 & 220,25 & 29,38 & 68,17 & 10,40 & 198,00 & 133,27 & 338,55 \\
14.07 .2011 & 64,80 & 6,72 & 1514 & 196,59 & 25,23 & 58,25 & 8,33 & 204,40 & 129,63 & 307,44 \\
26.11 .2011 & 63,00 & 6,48 & 1309 & 215,61 & 37,87 & 71,65 & 10,24 & 49,59 & 301,70 & 308,97 \\
23.04 .2012 & 60,00 & 7,18 & 1762 & 219,34 & 47,27 & 103,30 & 15,48 & 59,89 & 427,27 & 359,29 \\
25.07 .2012 & 58,90 & 6,93 & 1626 & 255,12 & 43,81 & 73,35 & 12,81 & 57,11 & 355,55 & 353,80 \\
25.08 .2012 & 60,60 & 7,35 & 1627 & 263,28 & 51,70 & 86,95 & 13,21 & 59,21 & 352,07 & 320,19 \\
03.11 .2012 & 57,40 & 7,21 & 1630 & 211,02 & 37,49 & 69,85 & 10,46 & 58,48 & 361,09 & 319,64 \\
30.03 .2013 & 56,00 & 7,36 & 1811 & 262,85 & 95,70 & 89,50 & 13,14 & 62,60 & 482,07 & 315,43 \\
\hline
\end{tabular}

Major anyon/katyon analiz sonuçları, su tipini belirlemek üzere Piper ve Schoeller hidrojeokimsayal değerlendirme amaçlı sayısal diyagramlarına aktarılmıştır. Alandaki termal su tipleri incelendiği, Naşa jeotermal alanındaki N-1 kuyusundaki su tipi $\mathrm{Ca}^{+2}-\mathrm{SO}_{4}^{-2}-\mathrm{HCO}_{3}^{-}$tipi olarak belirlenmiştir (Şekil 9).
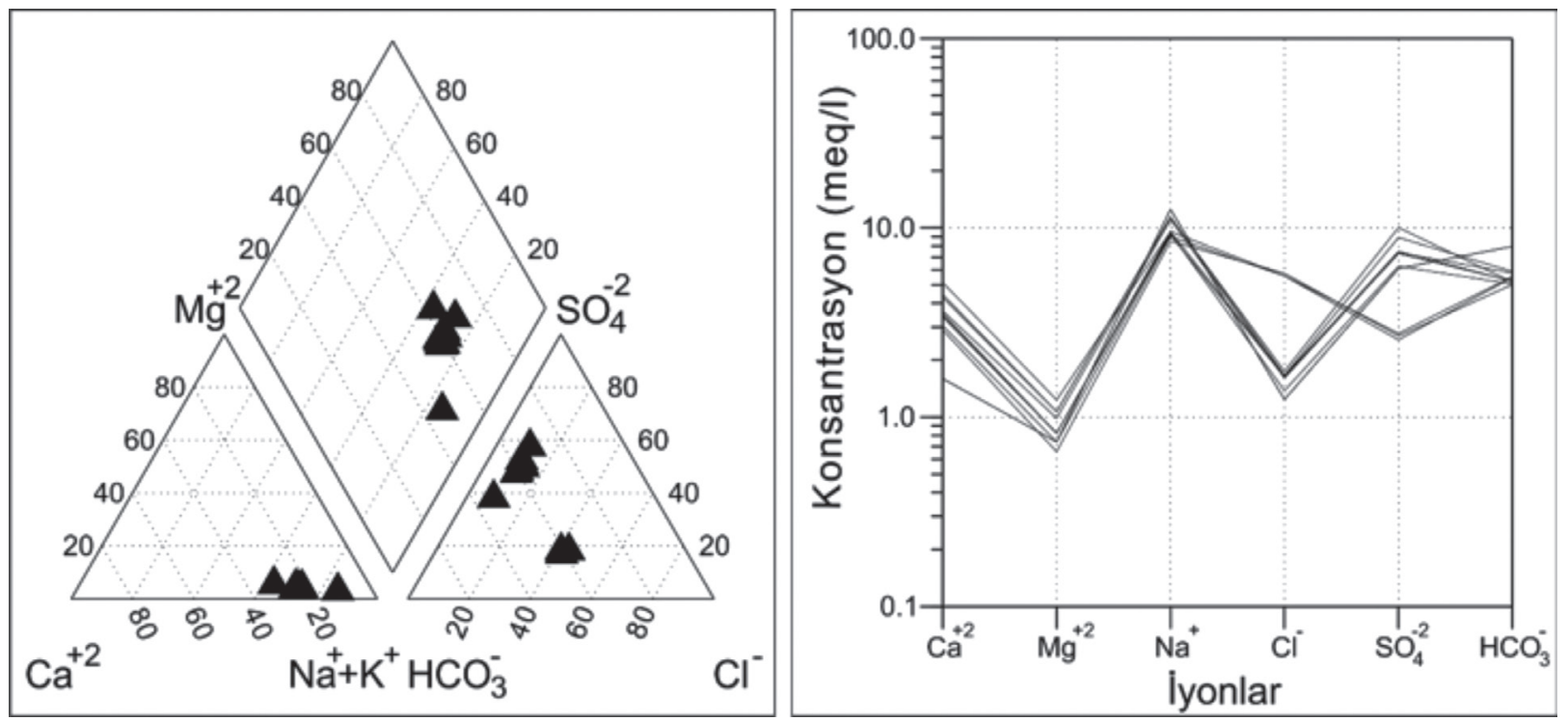

Şekil 9. Naşa kaynağından alınan verilere göre hazırlanmış Piper ve Schoeller Diyagramları

Figure 9. Piper and Schoeller diagrams of Eynal thermal water 


\section{Çitgöl (Simav) Jeotermal Alanı}

Çitgöl jeotermal alanı, Simav (Kütahya) ilçe merkezinin yaklaşık $5 \mathrm{~km}$ kuzeybatısında yer almaktadır. Naşa jeotermal alanında MTA nın 1985 yılında açmış olduğu yaklaşık $100 \mathrm{~m}$ derinliğindeki Ç-1 nolu sondaj kuyusundan yerinde ölçüm ve su örneklemesi yapılmıştır (Şekil 10). Bu sondaj kuyusundan 3 yıl içerisinde 10 örnekleme döneminde yerinde ölçüm ve su örnekleme çalışması yapılarak suların fiziksel ve kimyasal özellikleri belirlenmiştir (Tablo 5).

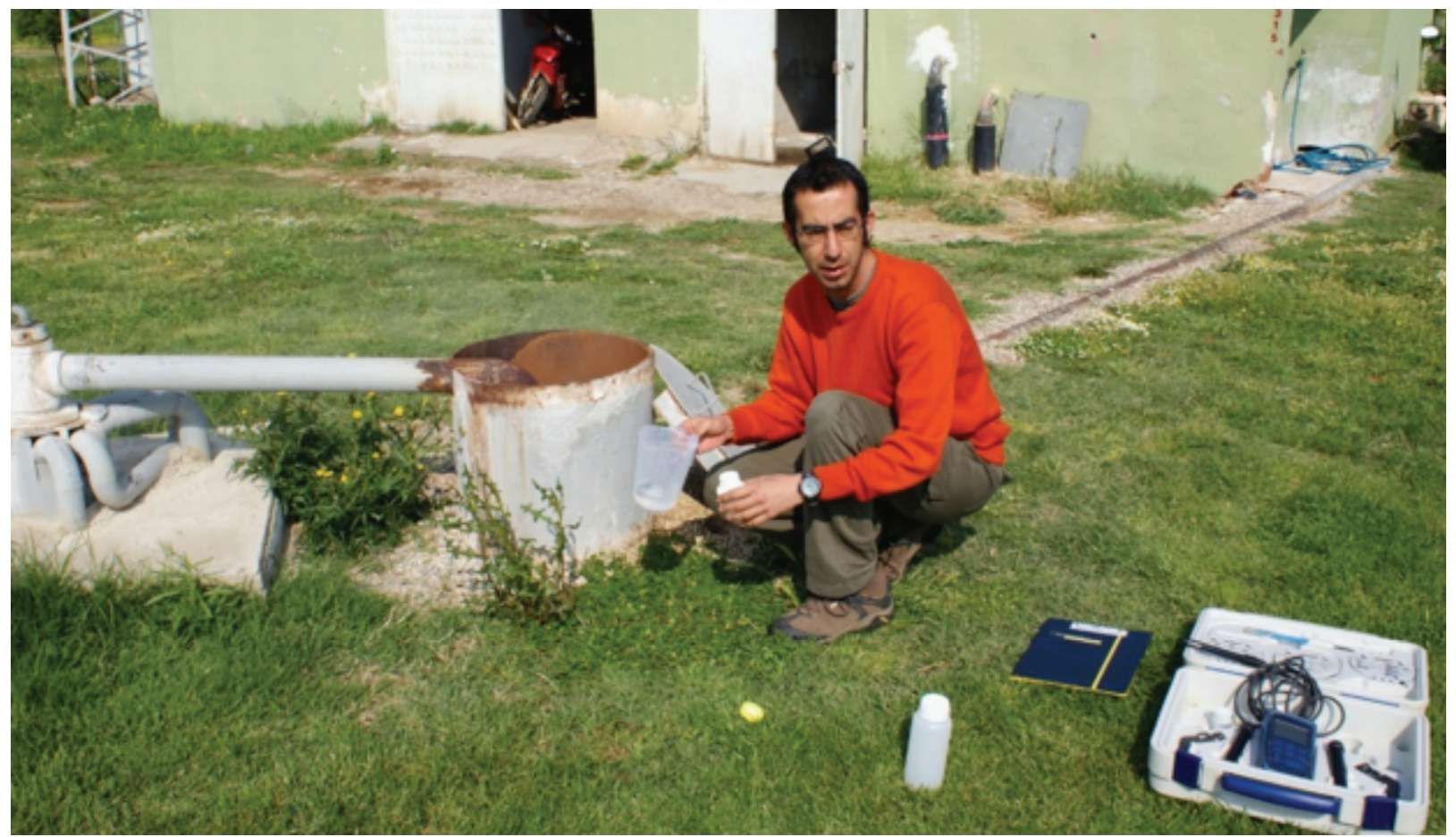

Şekil 10. Çitgöl Jeotermal Alanı (Ç-1 Kuyusu)

Figure 10. Çitgöl Geothermal Field (Ç-1 Drilling)

Çizelge 5. Çitgöl Jeotermal Alanındaki sıcak suların majör iyon derişimleri

Table 5. Major ion concentration of thermal water in Çitgöl Geothermal Field

\begin{tabular}{ccccccccccc}
\hline Tarih & $\begin{array}{c}\mathbf{T} \\
\left({ }^{\circ} \mathbf{C}\right)\end{array}$ & $\mathbf{p H}$ & $\begin{array}{c}\mathbf{E C} \\
(\boldsymbol{\mu S} / \mathbf{c m})\end{array}$ & $\begin{array}{c}\mathbf{N a}^{+} \\
(\mathbf{m g} / \mathbf{l})\end{array}$ & $\begin{array}{c}\mathbf{K}^{+} \\
(\mathbf{m g} / \mathbf{l})\end{array}$ & $\begin{array}{c}\mathbf{C a}^{+2} \\
(\mathbf{m g} / \mathbf{l})\end{array}$ & $\begin{array}{c}\mathbf{M g}^{+2} \\
(\mathbf{m g} / \mathbf{l})\end{array}$ & $\begin{array}{c}\mathbf{C l}^{-} \\
(\mathbf{m g} / \mathbf{l})\end{array}$ & $\begin{array}{c}\mathbf{S O}_{4}^{-2} \\
(\mathbf{m g} / \mathbf{l})\end{array}$ & $\begin{array}{c}\mathbf{H C O}_{\mathbf{3}}^{-} \\
(\mathbf{m g} / \mathbf{l})\end{array}$ \\
\hline 28.05 .2010 & 79,30 & 6,84 & 1736 & 178,69 & 24,13 & 26,32 & 3,37 & 28,55 & 187,65 & 318,00 \\
13.05 .2011 & 69,20 & 7,61 & 1632 & 252,05 & 29,30 & 29,19 & 3,30 & 211,60 & 112,19 & 334,89 \\
21.05 .2011 & 60,00 & 7,59 & 1655 & 252,30 & 29,72 & 35,51 & 4,33 & 206,40 & 128,75 & 312,32 \\
14.07 .2011 & 79,90 & 7,45 & 1740 & 265,80 & 33,09 & 26,49 & 2,79 & 218,40 & 124,71 & 330,01 \\
26.11 .2011 & 64,00 & 7,44 & 1860 & 241,90 & 53,55 & 43,08 & 5,11 & 62,30 & 406,24 & 313,24 \\
23.04 .2012 & 61,00 & 7,45 & 1526 & 227,50 & 31,83 & 37,48 & 6,60 & 39,61 & 269,19 & 326,66 \\
25.07 .2012 & 78,70 & 7,51 & 1935 & 266,81 & 60,61 & 37,05 & 3,61 & 71,10 & 455,98 & 336,72 \\
25.08 .2012 & 78,40 & 7,76 & 1961 & 253,45 & 59,62 & 37,41 & 2,78 & 68,74 & 419,76 & 315,26 \\
03.11 .2012 & 60,90 & 7,35 & 1744 & 208,24 & 35,22 & 33,66 & 4,49 & 51,85 & 338,58 & 295,55 \\
30.03 .2013 & 65,20 & 7,48 & 1729 & 227,50 & 72,70 & 32,16 & 3,76 & 61,27 & 400,24 & 302,74 \\
\hline
\end{tabular}


Major anyon/katyon analiz sonuçları su tipini belirlemek üzere Piper ve Schoeller hidrojeokimsayal değerlendirme amaçlı sayısal diyagramlarına aktarılmıştır. Alandaki termal su tipleri incelendiğinde, Çitgöl jeotermal alanındaki Ç-1 kuyusundaki su tipi $\mathrm{Na}^{+}-\mathrm{SO}_{4}^{-2}-\mathrm{HCO}_{3}^{-}$tipi olarak belirlenmiştir (Şekil 11).

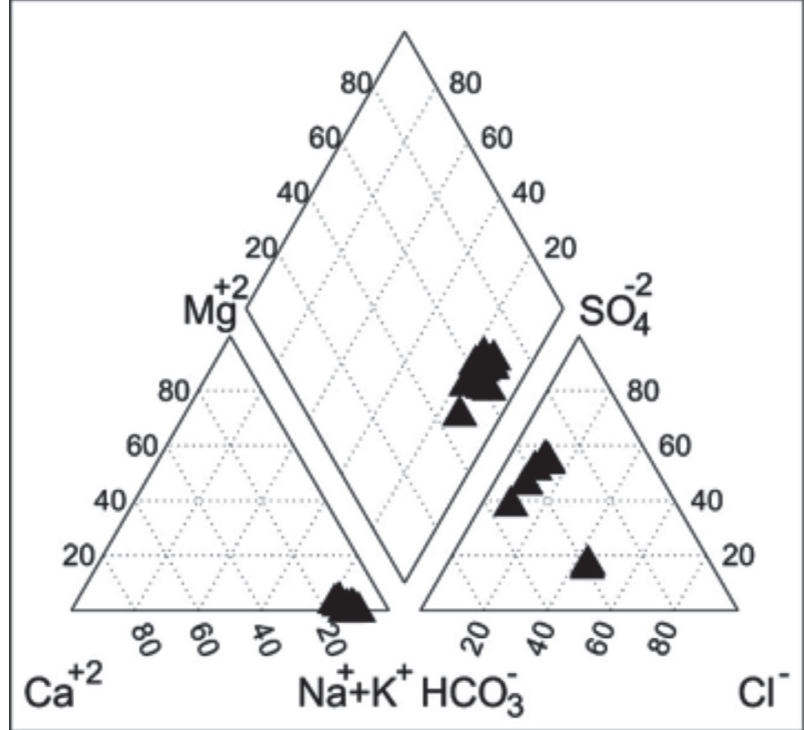

gelmiştir. Bunların en belirgin olanları her üç kaynakta da $\mathrm{Cl}^{-}$ve $\mathrm{SO}_{4}^{-2}$ iyon değerlerindeki değişimlerdir (Şekil 12) (Ateş ve diğ., 2011; Ateş ve diğ., 2012). Bu değişimleri genel olarak 5.0 ve daha büyük depremlerde gözlenmiştir. Örnekleme dönemlerinin en önemlileri 19 Mayıs 2011 de meydana gelen $\mathrm{M}=5.9$ büyüklüğündeki depremden

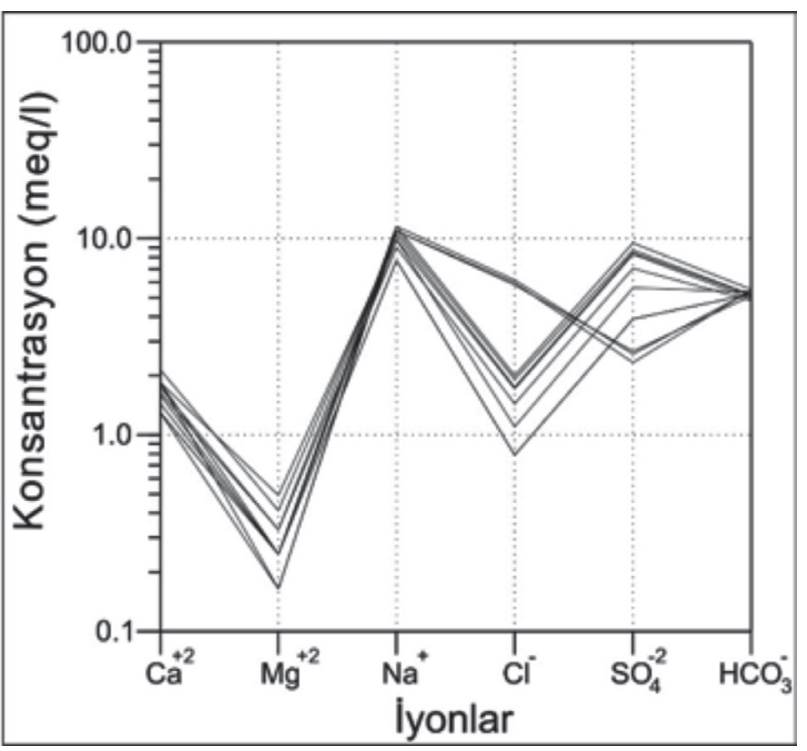

Şekil 11. Çitgöl kaynağından alınan verilere göre hazırlanmış Piper ve Schoeller diyagramları

Figure 11. Piper and Schoeller diagrams of Çitgöl thermal water

Derin jeotermal sularda sülfat $\left(\mathrm{SO}_{4}^{-2}\right)$ miktarı azdır. Yüzeye yakın yerlerde hidrojen sülfürün yükseltgenmesi ile artış gösterir $\left(\mathrm{H}_{2} \mathrm{~S}+2 \mathrm{O}_{2}=2 \mathrm{H}^{+}+\mathrm{SO}_{4}^{-2}\right)$. Klorür $\left(\mathrm{Cl}^{-}\right)$, jeotermal sistemlerin aranması ve yorumlanmasında çok kullanılan bir iyondur. Bir kez çözüldükten sonra başka minerallerin bünyesine kolay girmemesi nedeniyle doğrudan jeotermal suyu karakterize eder (Nicholson, 1993). Yüksek derişim doğrudan, derinden ve yüksek debili bir beslenmeyi gösterir. Düşük klorür derişimi yüzey sularının giriş doğrultularını belirtir (Eroğlu ve Aksoy, 2003).

Çalışma alanındaki üç farklı sıcak su kaynaklarının hidrojeokimyasalözellikleribölgede meydana gelen depremler ile ilişkilendirildiğinde belirgin fiziksel ve kimyasal değişikler meydana bir hafta önce ve 2 gün sonrası olanlarıdır. 13 Mayıs 2011 tarihindeki örnekleme dönemi sonrası alınan örneklerdeki $\mathrm{SO}_{4}^{-2}$ değerindeki belirgin azalış ve $\mathrm{Cl}^{-}$değerindeki belirgin artış trendi bölgedeki depremsellikle ilişkilidir. Benzer artış ve azalış davranışları 27 Haziran 2011 tarihinde meydana gelen $\mathrm{M}=5.0$ büyüklüğündeki ve 3 Mayıs 2012 tarihinde meydana gelen $\mathrm{M}=5.4$ büyüklüğündeki depremler öncesi ve sonrası da elde edilmiştir. $\mathrm{Bu}$ tarihten sonra bölgede deprem aktivitesi oldukça azalmış, genel olarak bölgede $\mathrm{M}<3$ büyüklüğünde depremler meydana gelmektedir. Temmuz 2012 ve bu tarihten sonraki örnekleme dönemlerinde alınan su örneklerinin analiz sonuçları da azalan deprem aktivitesine uygun olarak durağan bir gidiş göstermektedir (Şekil 12). 


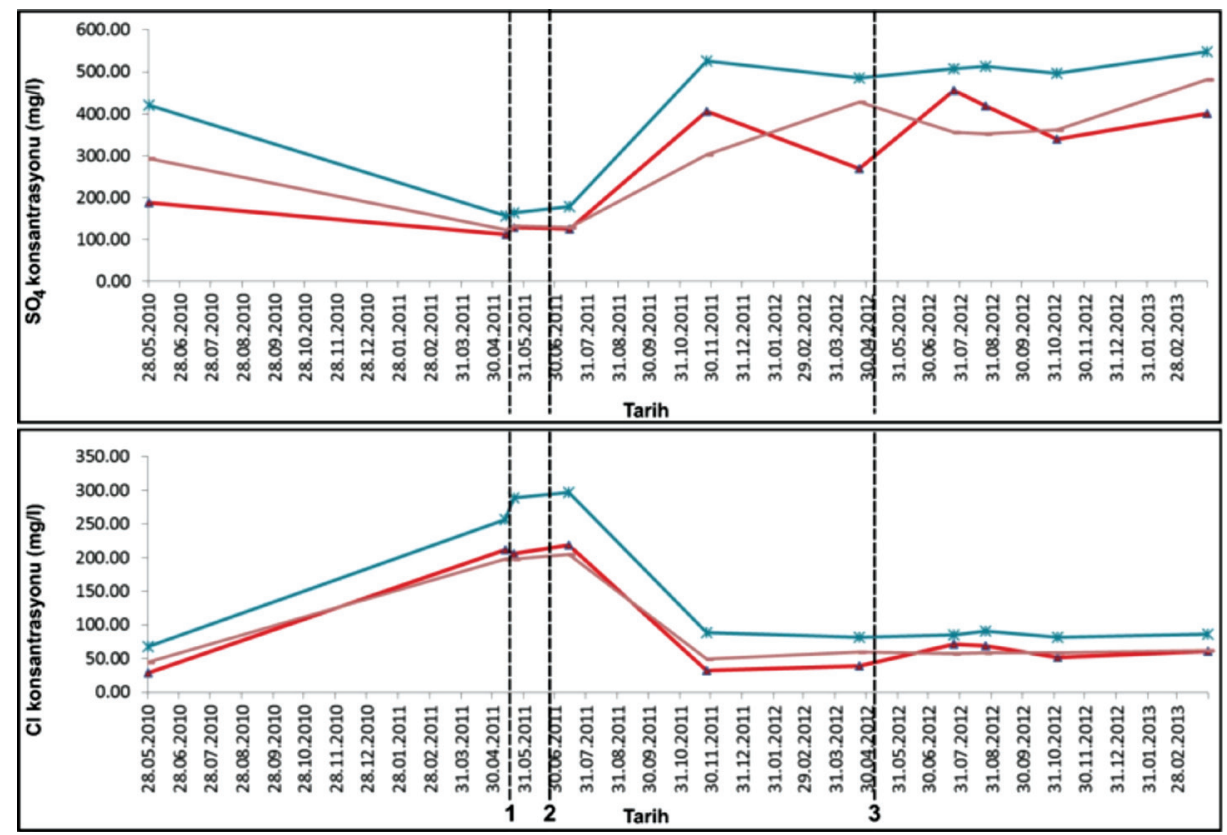

Şekil 12. $\mathrm{SO}_{4}^{-2} \mathrm{ve} \mathrm{Cl}^{-}$iyon değerlerindeki depremselliğe bağlı değişimler 1. 19 Mayıs 2011 depremi (M=5.9) 2. 27 Haziran 2011 depremi ( $M=5.0)$ 3. 03 Mayıs 2012 depremi $(M=5.4)$

Figure 12. $\mathrm{SO}_{4}^{-2}$ ve $\mathrm{Cl}^{-}$ion concentration changes connected with seismicity 1. 19 May 2011 earthquake (M=5.9) 2. 27 June 2011 earthquake $(M=5.0)$ 3. 03 May 2012 earthquake $(M=5.4)$

\section{TARTIŞMA ve SONUÇ}

Bu çalışmada Kütahya ili, Simav ilçesi kuzeyinde kalan Eynal, Çitgöl ve Naşa jeotermal alanlarında belirlenen sicak su sondajlarında Mayıs 2010-Mayıs 2013 tarihleri arasında 10 örnekleme döneminde yerinde ölçüm ve su örneklemesi çalışmaları yapılmıştır. Örnekleme dönemleri; 28 Mayıs 2010, 13 Mayıs 2011, 21 Mayıs 2011, 14 Temmuz 2011, 26 Kasim 2011, 23 Nisan 2012, 25 Temmuz 2012, 25 Ağustos 2012, 03 Kasım 2012 ve 30 Mart 2013 tarihlerine karşıllk gelmektedir.

Çalışma alanı ve yakın çevresinde, çalışmanın başladığ tarihinden, May1s 2013 tarihine kadar $\mathrm{M} \geq 3$ büyüklüğünde yaklaşı 735 adet deprem meydana gelmiştir. 19 Mayıs 2011 tarihinde saat 20:15 te Simav merkezli $\mathrm{M}=5.9$ büyüklüğündeki deprem de dahil 3 adet $M=5.0$ ve $M>5.0$ büyüklüğünde 3 adet deprem meydana gelmiştir.
Çalışma alanında meydana gelen depremler ile termal sulardaki fiziksel ve/veya kimyasal değişimler korele edilmiştir. Buna göre üç jeotermal alandaki sıcak sularda da fiziksel ve kimyasal değişikler meydana geldiği görülmüştür.

Sicak suların fiziksel özellikleri kapsamında; en belirgin değişimler sıcaklık değerlerinde gözlenmiştir. Çitgöl jeotermal alanında depremden bir hafta önce suların sıcaklık değeri $10 \mathrm{C}^{\circ}$ azalmıştır ve depremden 2 gün sonra bu değer $9 \mathrm{C}^{\circ}$ daha azalmıştır. Naşa jeotermal alanında ise suların sıcaklık değeri $10 \mathrm{C}^{\circ}$ artmıștır.

Sicak suların kimyasal özellikleri kapsamında; hemen hemen tüm alanlardaki suların $\mathrm{Cl}^{-}$iyon değerleri büyük depremler öncesi yaklaşık beş kat artmıştır. Sıcak sularda $\mathrm{Cl}^{-}$iyon değeri ne kadar fazla olursa sular o kadar fazla derin dolaşımlı olduğu sonucunu vermektedir. Depremin etkisi ile derin kökenli bir beslenmeye ilişkin olduğu düşünülmüştür. 
Ayrica sicak sulardaki $\mathrm{SO}_{4}^{-2}$ iyon değerlerinde de büyük depremler öncesi bir azalma meydana gelmiştir. $\mathrm{SO}_{4}^{-2}$ iyon değeri deprem öncesinde azalma trendine girmiştir. Çünkü sülfür $\left(\mathrm{S}^{-3}\right), \mathrm{SO}_{4}^{-2}$ iyonuna yükseltgenmeyip, gaz olarak yüzeye ulaşmıştır. Deprem sonrasında ise HS ve/veya jeotermal akış fazında gözlenen $\mathrm{H}_{2} \mathrm{~S}$ gazının normal düzeyine dönmeye başlamasıyla yeniden suda $\mathrm{SO}_{4}^{-2}$ olarak çözünmeye başladığı düşünülmektedir.

Sicak sulardaki bu değişimler sadece 19 Mayıs 2011 tarihinde olan $\mathrm{M=5.9}$ büyüklügüündeki depremin etkisiyle gözlenmemiştir. 27 Haziran 2011 tarihinde $\mathrm{M}=5.0$ ve 3 May1s 2012 tarihinde $\mathrm{M}=5.4$ büyüklüklerinde depremleri hemen öncesi ve sonrası da benzer değişimler gözlenmiştir.

Elde edilen bu veriler 1şığında, jeotermal sistemleri de içeren sismik açıdan aktif bir bölgede, sıcak sular sürekli izlenebilirse, olası bir depremin öncesinde jeotermal sistemdeki sıcak sulardaki fiziko-kimyasal değişimler sayesinde bir depremin önceden tahmin edileceği ortaya çıkmıştır.

\section{KATKI BELİRTME}

Bu çalışma Çanakkale Onsekiz Mart Üniversitesi, Bilimsel Araştırma Projeleri Koordinasyon Birimi (ÇOMÜ-BAP) 2010/166 nolu proje kapsamında gerçekleştirilmiştir. Ayrıca arazi çalışmaları ile verilerin yorumlanması sirasında desteklerinden dolayı Prof. Dr. Süha ÖZDEN'e teşekkürü bir borç biliriz.

\section{EXTENDED SUMMARY}

It is known that changes in groundwater concentrations start with first shake and reach maximum level with energy discharge than become normal levels by time after earthquakes. Occurring of new springs or disappears of existing springs can be seen before, during or after earthquakes. We should know detail geological features of geothermal fields to use changings in hot or mineral water concentrations as earthquake estimation before. In this scope, a monitoring study is done from thermal water springs which located along the Simav Fault to follow up these springs in the frame of physical and geochemical features and relationship with seismicity. Study area is located around Simav (Kütahya) (Middle West Anatolia) northern of Simav Fault and indicated as an active fault zone in the active fault map of Turkey is fairly active region in terms of earthquakes occurred in the instrumental period. This area also has many thermal areas which located on active faults. These are Naşa, Çitgöl and Eynal geothermal fields located north of Simav.

The study area and its vicinity geologically represent the northern part of Menderes Massif. At the present time this area is restricted by Simav Fault. On the basement of the study area consist of Paleozoic aged Menderes Massif which has gneiss, migmatite and schist type metamorphic rocks. In the north of these metamorphic rocks, Oligo-Miocene plutonic rocks are located. These geological units overlying by Miocene volcanic, clastic and carbonate rocks which have widespread. Plio-Quaternary aged Naşa basalt is the youngest volcanic activity of the area. All these rocks are covered by Quaternary aged alluvium.

Most of faults are normal fault which observed in the study area and general strike of these faults is NW-SE, WNW-ESE and E-W. The most important and active of these faults is Simav Fault which continues along the south of study area. It has WNW-ESE strike, $N$ dip and about $60 \mathrm{~km}$ length. It is known that fault's initial movement is right-lateral strike slip but in Quaternary due to the general NNE-SSW extensional regime in western Anatolia, a regime change has been exposed 
and present Simav fault has been working as a normal fault.

Due to high seismic activity of Simav and surrounding area, many big earthquakes occurred in the instrumental period. Around the study are about 1000 earthquakes occurred which has $M>3$ magnitude between May 2010 and May 2013. Most important and destructive earthquake of these was 19 May 2011 M=5.9 earthquake. Also on June 27, 2011 and May 3, 2012 at M=5.0 and $M=5.4$ magnitude earthquakes occurred.

In this study, three thermal springs determined in Naşa, Çitgöl and Eynal geothermal areas. Sampling and in-situ measurements were done from these thermal waters in 10 different periods from May 2010 to May 2013. Due to geochemical analysis of thermal waters Naşa spring is $\mathrm{Ca}^{+2}-\mathrm{SO}_{4}^{-2}-\mathrm{HCO}_{3}^{-}$type, Çitgöl spring is $\mathrm{Na}^{+}$$\mathrm{SO}_{4}^{-2}-\mathrm{HCO}_{3}^{-}$type and Eynal spring is $\mathrm{Na}^{+} \mathrm{SO}_{4}^{-2}$ $\mathrm{HCO}_{3}^{-}$type of water.

Also physical and/or chemical changes in thermal water springs are compared between earthquakes. According to this monitoring study many physical (temperature increase and decrease) and chemical (increasing and decreasing of $\mathrm{Cl}^{-}$and $\mathrm{SO}_{4}^{-2}$ concentrations) changing happened in these three thermal springs. These changing are observed at especially after and before earthquakes which have $M=5.0$ and bigger. According to these data, in seismically active areas including geothermal systems, hot water can be continuously monitored; a possible earthquake can be predicted by changes in water hydrochemistry.

\section{DEĞİNILEN BELGELER}

Akdeniz N. ve Konak N., 1979b. Simav-Emet-Tavşanlı -DursunbeyDemirci yörelerinin jeolojisi, MTA Gen. Müd., Rapor No: 6547, Ankara.

Ateş, Ö., Özden, S. ve Tutkun, S.Z., 2011. Aktif fayların jeotermal alanlarla ilişkisine bir Örnek: 19 Mayıs 2011 Simav depremi ile jeotermal kaynaklardan elde edilen verilerin anlamı, ATAG 15. Çalıştayı Bildiri Özleri Kitabı, Adana, S:58.

Ateş, Ö., Özden, S. ve Tutkun, S.Z., 2012. Jeotermal kaynaklarda depremlere bağlı gözlenen değişikliklere bir örnek: 19 Mayıs 2011 Simav depremi ve etkileri, 65. Türkiye Jeoloji Kurultayı Bildiri Özleri Kitabı, sf 14-15.

Ercan, T., Günay, E. ve Savaşçın, M.Y., 1982. Simav ve çevresindeki Senozoyik yaşlı volkanizmanın bölgesel yorumlanması, MTA Dergisi, 97-98, 86-101.

Eroğlu, A ve Aksoy, N., 2003. Jeotermal suların kimyasal analizi, VI. Ulusal Tesisat Kongresi, Jeotermal Enerji Semineri Kitapçı̆̆ı, 149-183.

Gün, H., Akdeniz, N. ve Günay, E., 1979, Gediz ve Emet güneyi Neojen havzalarının jeolojisi ve yaş sorunları, Jeoloji Mühendisliği Derg., 8, 3-13.

Konak, N., 2002. 1/500000 ölçekli Türkiye Jeoloji Haritası İzmir Paftası, M.T.A., Ankara.

Nicholson, K.N., 1993. Geothermal Fluids, Chemistry and Exploration Techniques, $x v+263$ pp. Berlin, Heidelberg, New York, London, Paris, Tokyo, Hong Kong: Springer-Verlag. Price DM 138.00, Ös 1076.40, SFr 138.00 (hard covers). ISBN 3540560173.

Özden, S., Tutkun, S.Z., Bekler, T., Karaca, Ö., Komut, T., Kalafat, D., Ateş, Ö., Demirci, A.,

Gündoğdu, E. ve Çınar Yıldız, S., 2012. Simav Fayı ile Kütahya Fayı (Emet-Orta Batı Anadolu) arasında kalan bölgenin Neotektonik ve Sismotektonik özellikleri, TÜBİTAK 109 Y 103 nolu proje final raporu, $235 \mathrm{~s}$.

Şimşek, Ş. ve Yıldırım, N., 2000, Termal Kaynaklar: Depremin habercisi, 17 Ağustos ve 12 Kasım 1999 deprem bölgelerindeki termal kaynaklarda gözlenen değişimler ve önemi, Cumhuriyet, Bilim Teknik, 01 Temmuz 2000.

Yücel, B., Çoşkun, B., Demirci, S. ve Yıldırım, N., 1983, Simav yöresinin jeolojisi ve jeotermal enerji olanakları, MTA Der. Rap. No: 8219, 21s. www.deprem.gov.tr

$\begin{array}{lcc}\text { Makale Geliş Tarihi } & : & 29.04 .2014 \\ \text { Kabul Tarihi } & : & 07.07 .2014 \\ & & \\ \text { Received } & : & 29.04 .2014 \\ \text { Accepted } & : & 07.07 .2014\end{array}$

